\title{
GEOLOGIA GERAL NOS CURSOS DE GEOLOGIA E GEOGRAFIA: UMA COOPERAÇÃO POSSÍVEL
}

\author{
Rafael Celestino Soares ${ }^{(1)}$ Laryssa Sheydder de Oliveira Lopes ${ }^{(2)}$ Osmanda Moura Souza ${ }^{(3)}$ \\ Maria Rayssa Vieira Antunes ${ }^{(4)}$ \\ (1) Doutorando em Geologia, Universidade Federal do Ceará, E-mail: rafaelcsoares@yahoo.com.br \\ (2) Doutoranda em Geografia, Universidade Federal do Pernambuco, E-mail: sheydder@yahoo.com.br \\ (3) Graduada em Biologia, Universidade Regional do Cariri, E-mail: osmandamoura@hotmail.com \\ (4) Graduanda em Geografia. Universidade Regional do Cariri.
}

\section{Eixo: GEOGRAFIA FÍSICA: CURRÍCULO, FORMAÇÃO E PRÁTICAS DE ENSINO}

\begin{abstract}
Resumo
O curso de graduação em Geografia exerce diálogos com as Ciências Humanas, Exatas e da Terra, ideia que sugere aproximação estratégica com outros cursos. Analisando o desenvolvimento da disciplina 'Geologia Geral', no Curso de Geografia da Universidade Federal do Ceará, identificou-se uma ausência de práxis (inexistência de laboratórios e de aulas de campo) e alunos pouco motivados. Objetivando promover o ensino efetivo de temas geológicos no Curso de Geografia, foi proposta a cooperação de um curso de área afim em uma ação bastante simples. Os bolsistas do Programa de Pós Graduação em Geologia foram mediadores entre o curso que precisava de apoio e aquele que poderia ofertar esse apoio. Assim, solicitou-se ao Departamento de Geologia a liberação de um laboratório e a disponibilização de monitores para as aulas da disciplina 'Geologia Geral' do Departamento de Geografia. A partir das mudanças, observou-se aumento da motivação e melhor rendimento dos alunos.
\end{abstract}

Palavras chave: Ensino Superior, Geografia Física, Prática de Ensino, Rocha.

\section{Introdução}

A produção e a divulgação do conhecimento científico têm sido discutidas cada vez mais numa perspectiva plural e transdisciplinar, como uma estratégia eficaz para superar questões geradas pela especialização crescente no desenvolvimento científico (Portocarrero, 1998). Como bem salientou Demo (1997), transcender o conhecimento para além das fronteiras de qualquer ciência fortalece o saber específico, destaca pontos de convergência e permite ampliar a área de atuação, criando oportunidades de formação de equipes heterogêneas que facilitam a criatividade e a inovação.

O estudo sobre os minerais e rochas, a formação, estrutura e dinâmica da Terra constituem um dos conhecimentos elementares de várias áreas científicas, como a Engenharia Civil, a Agronomia, Biologia, Geografia e, naturalmente, a Geologia, ainda que oferecidas sob distintas designações e diferentes enfoques e ênfases. No bacharelado de Geologia da Universidade Federal do Ceará (UFC), essa disciplina se intitula 'Sistema Terra', sendo um dos pilares básicos na formação de todo geólogo. Por esta razão, é 
ministrada com muitas aulas teóricas e práticas, tanto em laboratório como no campo, pois os profissionais da área sabem da importância do contato visual e táctil com elementos rochosos para perceber suas características e assimilar inúmeros conceitos básicos. Já no curso de Geografia da UFC, esta disciplina é denominada 'Geologia Geral' e é ofertada apenas através de aulas teóricas, ainda que minerais e rochas componham o cotidiano de todos os alunos que estudam os processos atuantes na superfície de nosso planeta. Deste modo, um laboratório específico para a análise de componentes rochosos e ensaios geológicos experimentais torna-se desnecessário. A programação desta disciplina também não inclui excursões de campo, acentuando seu caráter eminentemente teórico e tornando a aprendizagem de seu conteúdo pouco atraente, o que é observável pelo relativo desinteresse dos estudantes em assistir integralmente as aulas.

Hessel (1990), ao analisar uma disciplina básica do curso de Geologia, identificou a necessidade de aulas práticas para alunos iniciantes nas universidades que não possuem ainda estruturas mentais de raciocínio operatório formal (sensu Piaget, 1976), sendo incapazes de 'partir do possível (da teoria) para o real (a prática)' e sabendo apenas como 'partir do real para alguns possíveis'. Assim, ao observar amostras geológicas reais, o aluno pode elaborar mentalmente lista de atributos para cada conceito, iniciando um exercício mental que perpassa pelas quatro operações do raciocínio formal: dedução, combinação, permutação e correlação. Como a autonomia científica do aluno depende muito de sua capacidade de raciocínio operatório formal, a oferta de aulas práticas é muito motivadora, especialmente se apresentarem desafios e questões que estimulem a descoberta.

Segundo Santos (1988), cada método é uma linguagem e a realidade nos responde na mesma forma em que é perguntada. Isto significa que métodos diferentes e inusitados costumam gerar curiosidade e interesse. Por isso, ideias inovadoras adotadas na academia podem colaborar para a melhoria do ensino, pois surpreendem os alunos com atividades inesperadas, que então respondem mostrando uma aprendizagem mais eficiente e duradoura. Santos sugere que o conhecimento científico da natureza, como é o saber geológico, é também um conhecimento social, ainda que ciências humanas e ciências naturais pareçam bastante distantes. Mas o ser humano e a sociedade se desenvolvem na superfície da Terra, interagindo cotidianamente com a natureza.

Se a interação homem/natureza for unilateral haverá desequilíbrio, com consequências nefastas para ambos os lados. Porém, se construirmos pontes e elos entre o desenvolvimento social e o desenvolvimento científico, a superação das diferenças de pólos aparentemente opostos, como cultura/natureza, subjetivo/objetivo, individual/coletivo, teoria/prática poderá ser alcançada. Assim, a união destes opostos, 
as pluralidades didáticas e metodológicas podem unir e cimentar fragmentos do conhecimento teórico exposto em sala de aula, contribuindo decisivamente para a melhoria da formação de recursos humanos.

\section{Diagnóstico da disciplina Geologia Geral no curso de Geografia}

Inicialmente, através da observação das aulas teóricas desta disciplina, procurou-se esclarecer e entender o contexto no qual o trabalho deveria ser realizado. Durante o primeiro mês, os bolsistas se revezaram propositalmente nessa tarefa, para ter uma percepção diferenciada da situação didático-pedagógica da disciplina. De acordo com Oliveira (2001), a diversidade de olhares permite construir práticas e saberes que ousam imaginar o não imaginado, e experimentar o não experimentado. A expectativa era de que o sucesso de uma iniciativa inovadora estaria no diálogo entre as diferentes percepções e linguagens, na integração dos saberes e vivências prévias.

Os aspectos observados pelos diferentes bolsistas, mesmo que de modo informal, foram posteriormente listados e discutidos de modo a formar um panorama próximo da realidade das aulas de 'Geologia Geral' no curso de Geografia da UFC. Foram observados os seguintes aspectos:

a) afinidade entre o conteúdo programático e os métodos de ensino adotados, considerando aspectos salientados por Hessel (1990), como:

- capacidade de autocrítica do professor referente às aulas expositivas, avaliações e exercícios, o que possibilita a elaboração mais acurada de recursos e materiais didáticos

- segurança e desenvoltura do professor em sala de aula, pois o medo de críticas e de não alcançar os objetivos propostos pela disciplina podem se tornar um bloqueio na relação professor-aluno

- flexibilidade do professor para colocar em prática novas ideias e procedimentos didáticos, o que pode tornar as atividades desenvolvidas mais atraentes

- motivação do professor para ministrar as aulas, pois uma atividade desenvolvida só é convincente e satisfatória quando se acredita naquilo que se está realizando (Siqueira Neto, 2006).

b) didática das atividades teóricas/práticas: considerando que o planejamento das aulas e a atualização do conteúdo, apesar de invisível aos estudantes, é essencial para atingir os objetivos de uma disciplina, foi avaliado especialmente o equilíbrio do tempo despendido entre as aulas expositivas e realização de exercícios ou apresentação de vídeos.

c) adaptação do plano de ensino ao curso de Geografia: uma vez que o programa da disciplina é bastante extenso, critérios para estabelecer a relevância dos diversos temas a serem abordados 
deveriam ser relacionados a questões geográficas, o que não ocorria, gerando dificuldades de interesse e aprendizagem nos estudantes.

d) percepção das aulas pelos estudantes: a conversa com os alunos revelou a causa da dispersão e evasão observadas, pois eles percebiam que a disciplina não era importante para a formação de um geógrafo, considerando que, para eles, a Geografia participa das ciências humanas, devendo assim ser direcionada ao espaço socialmente produzido; esta percepção dos estudantes foi relevante para explicar muitas das dificuldades e necessidades observadas.

Esta concepção dos alunos de que a Geografia pertence às ciências humanas advém de uma visão equivocada, revelando um conhecimento fragmentário, pouco integrado, baseado na dicotomia natureza versus sociedade/cultura. De acordo com Santos (2001), conforme a evolução tecnológica foi transmutando a natureza num artefato construído pelo ser humano, a cultura passou de artefato artificial intrometido no mundo natural para se tornar a expressão do artefato global, o que se explica porque a natureza, enquanto objeto de conhecimento, sempre foi considerada uma entidade de desenvolvimento cultural e assim participante das ciências sociais. Entretanto, as ciências da natureza, como a Geologia e Biologia, formam a base para o desenvolvimento da humanidade e de sua cultura, sendo, portanto, indissociável das ciências humanas.

\section{Cooperação Interdepartamental}

Com base nas observações efetuadas, foi desenvolvido um trabalho em conjunto com o professor da disciplina 'Geologia Geral' visando adequar os conteúdos apresentados em sala de aula às múltiplas atividades que poderão ser desenvolvidas pelos alunos como futuros geógrafos. Assim, foi abandonado o programa adotado, que era o mesmo da disciplina 'Sistema Terra' do curso de Geologia, e proposta uma nova abordagem do conteúdo programático, seguindo a proposta por Ferreira (1990).

A transdisciplinaridade, como prática de unir as diferenças do saber e diversas linguagens (Morin, 1999), foi então a ferramenta adotada de comunicação entre a Geologia e a Geografia, possibilitando a intersecção entre estes dois campos do conhecimento (Fig.1). Assim, foi possível superar um modelo bastante reducionista (programa idêntico para ambos os cursos) e desfocado do contexto da Geografia. 


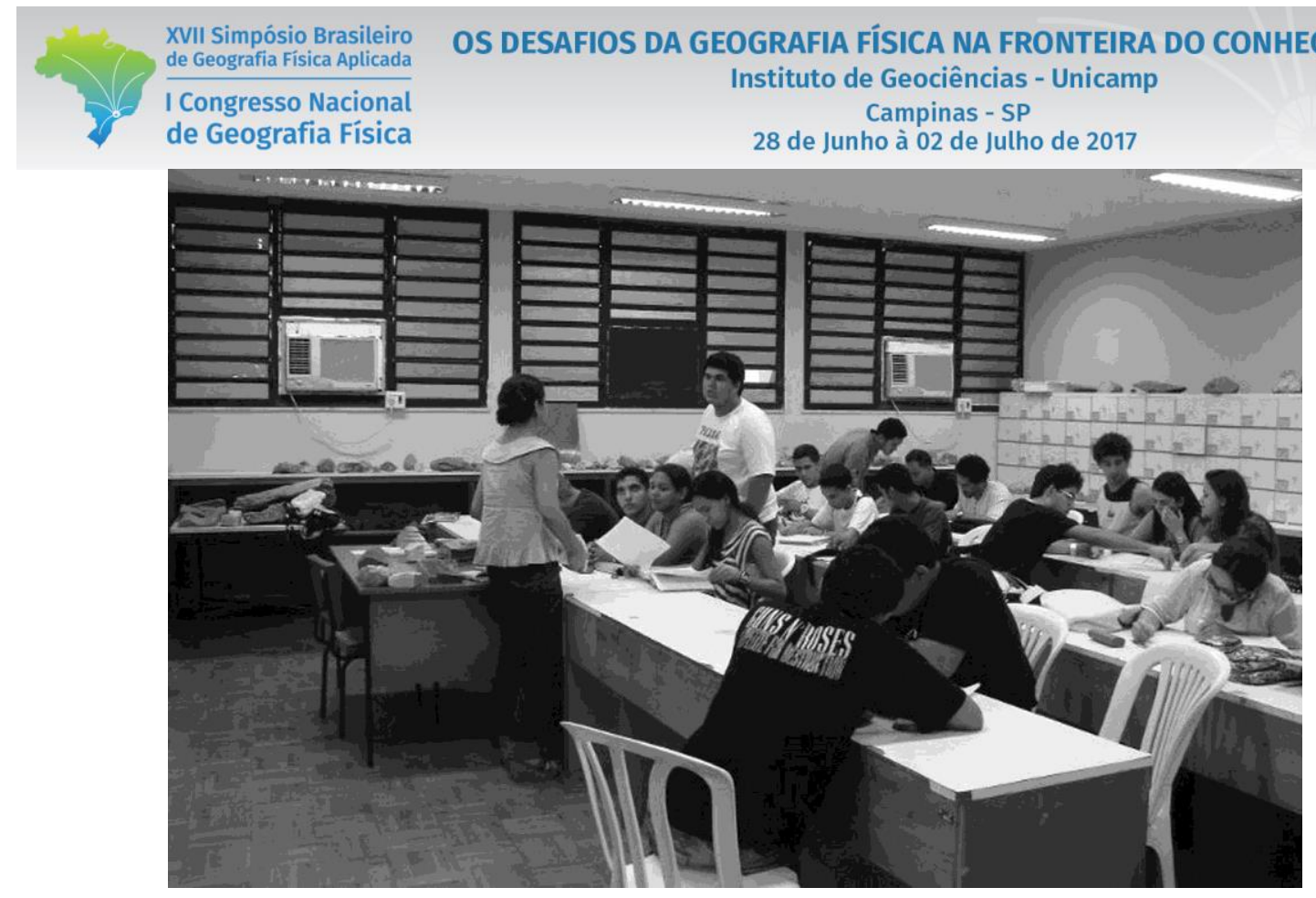

Figura 1- Alunos do curso de Geografia no Laboratório de Minerais e Rochas do Curso de Geologia da UFC.

Outra forte razão identificada pelos bolsistas PROPAG para que a disciplina 'Geologia Geral' fosse pouco motivadora e de difícil aprendizado para alunos do curso de Geografia da UFC foi a ausência de aulas práticas, indispensáveis quando se trabalha com conceitos na fase inicial da vida acadêmica, como bem demonstrou Hessel (1990). Conhecedores de como era lecionada a disciplina correspondente no Departamento de Geologia e de que este dispunha de um laboratório para lecionar as aulas práticas de Geologia, os bolsistas PROPAG idealizaram um projeto de cooperação interdepartamental para sanar esta lacuna. O projeto amparou-se na justificativa de que a base de todo conteúdo geológico está no conhecimento prévio das rochas e de seus elementos constituintes. As classes de minerais com suas propriedades físicas e os tipos de rochas com suas características são temas que exigem a visualização de suas feições e a manipulação de variadas amostras para seu reconhecimento e distinção (Fig.2). Era também a possibilidade de transformar um conhecimento mental e teórico (aquilo que é simplesmente visto e idealizado em ilustrações) em um produto real, material (resultado da associação da ideia com o objeto), o que estimula a construção de uma identidade do objeto (Seemann, 2003) e facilita seu reconhecimento posterior através de conceitos internalizados. 


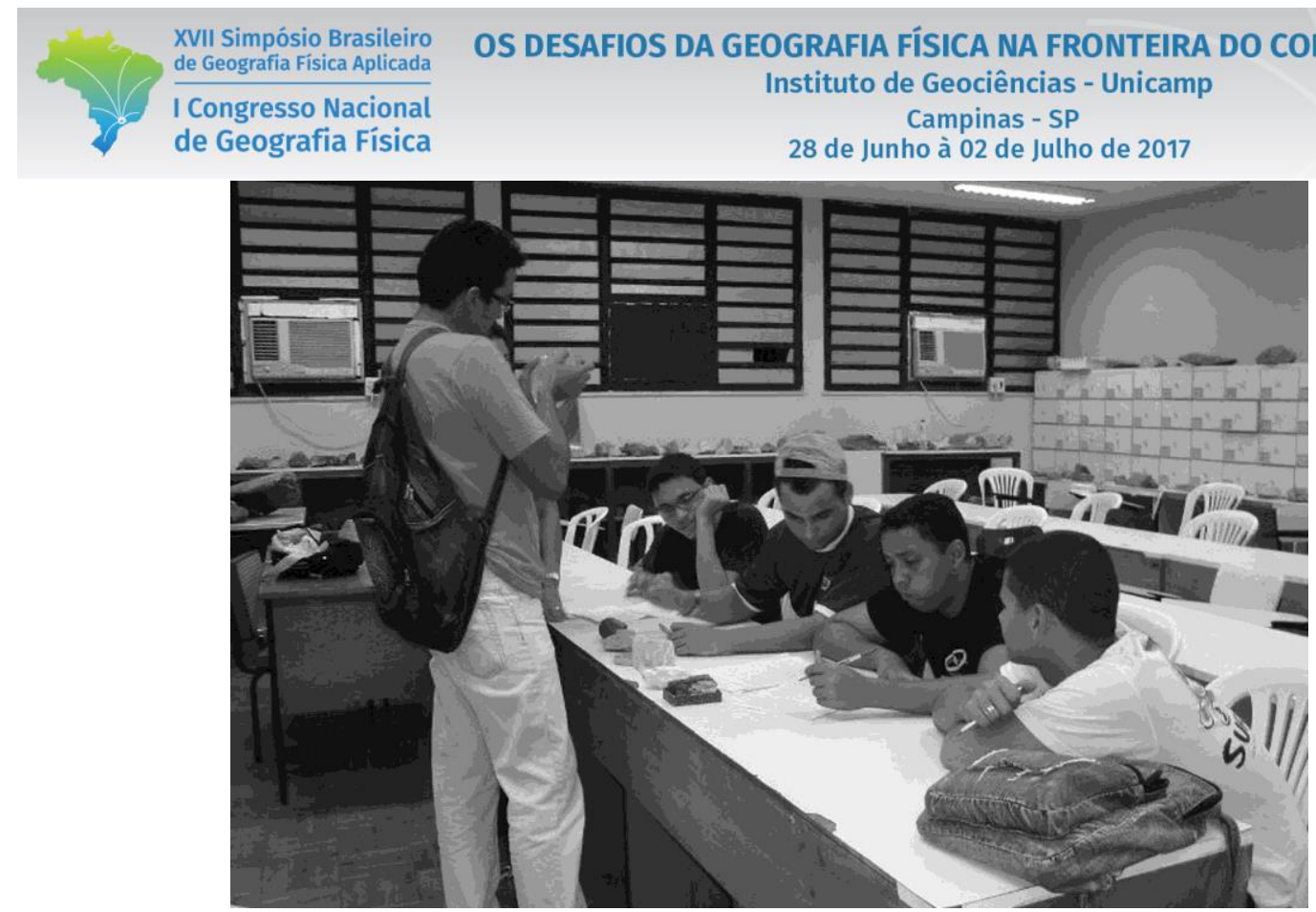

Figura 2 - Alunos do curso de Geografia analisando amostras no Laboratório de Minerais e Rochas da UFC.

Os procedimentos adotados pelos bolsistas para efetivar esta ideia de cooperação exigiram a mediação entre o curso requerente de apoio (Geografia) e aquele que poderia ofertar o apoio requerido (Geologia). Foi então solicitada à coordenação de graduação do curso de Geologia a liberação do Laboratório de Minerais e Rochas para aulas práticas de 'Geologia Geral' do curso de Geografia incluindo o auxílio dos serviços de monitoria já atuante no laboratório, sempre quando possível. Com as autorizações obtidas, foi elaborado um cronograma de atendimento no Laboratório de Minerais e Rochas em horários nos quais não havia atividade programada. Este atendimento foi oferecido aos estudantes de Geografia pelos bolsistas PROPAG juntamente com os monitores já designados pelo Departamento de Geologia.

As aulas práticas seguiram a dinâmica já existente na disciplina 'Sistema Terra', mas com a preocupação de adaptar o conhecimento geológico aos interesses dos alunos de Geografia, deste modo inovando em sua abordagem. A prática em laboratório foi planejada de tal forma que contemplassem dois momentos para um mesmo tema. O primeiro consistiu na explanação do conteúdo, revisando temas das aulas teóricas, e um primeiro contato com objetos de estudo a eles relacionados. O segundo momento foi constituído por exercícios práticos e questões a serem resolvidas por alunos em pequenos grupos através da análise de amostras de minerais e rochas, o que permitiu materializar as ideias teóricas em pauta e incorporar mais efetivamente o conteúdo antes lecionado (Fig.3).

Para a realização destas aulas práticas, a turma foi dividida em grupos considerando não somente a capacidade física do Laboratório de Minerais e Rochas do Departamento de Geologia, mas também a quantidade de monitores disponíveis para auxiliar na realização dos exercícios e esclarecer dúvidas. Como 


\section{OS DESAFIOS DA GEOGRAFIA FÍSICA NA FRONTEIRA DO CONHECIMENTO \\ Instituto de Geociências - Unicamp \\ Campinas - SP \\ 28 de Junho à 02 de Julho de 2017}

os bolsistas PROPAG atores deste processo possuem formação acadêmica diversificada (um geógrafo, uma geóloga e uma bióloga), foram juntos capazes de construir uma linguagem facilmente assimilável pelos alunos, permeando os temas teóricos e as práticas desenvolvidas numa visão transdisciplinar de produzir ciência.

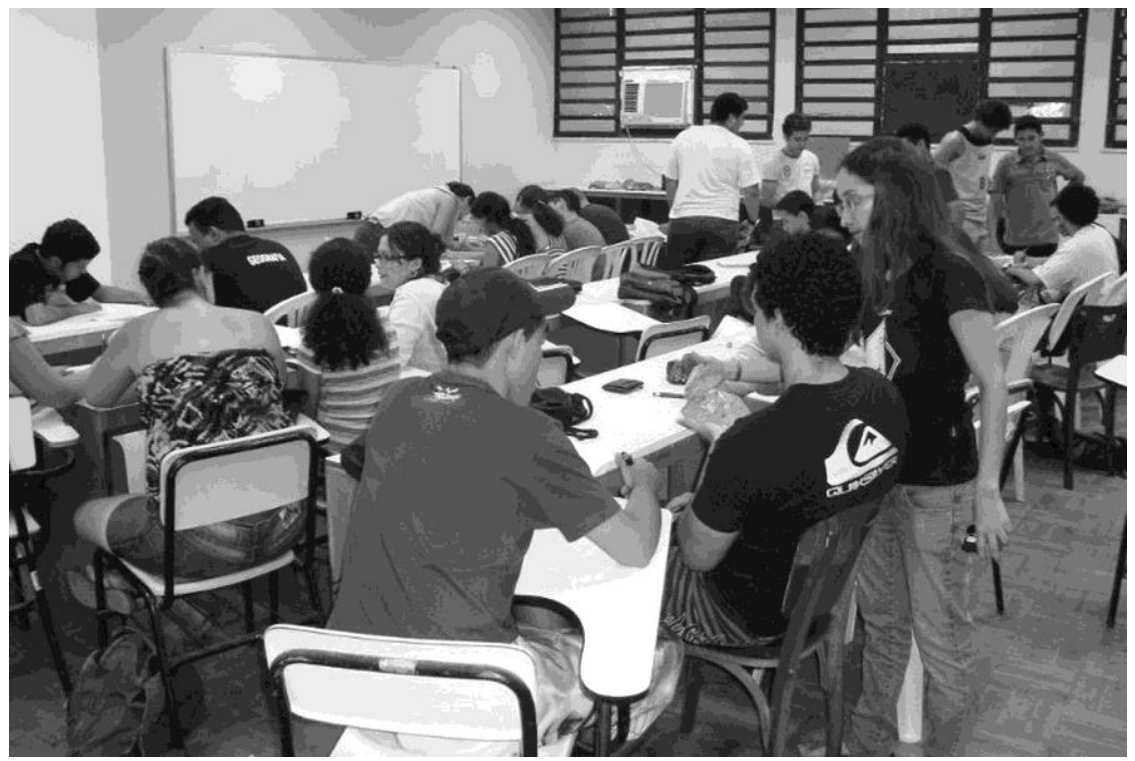

Figura 3: Aula prática dos alunos do curso de Geografia no Laboratório de Minerais e Rochas da UFC.

Com a oferta de aulas práticas de 'Geologia Geral' no Laboratório de Minerais e Rochas da UFC, o curso de Geologia também obteve benefícios, pois a proposta contemplou a reorganização do espaço de estudo para que os alunos, tanto do curso de Geologia como de Geografia, tivessem um acesso mais direto ao material didático, assim como a atualização e aumento da coleção de amostras disponibilizadas para estudo. Com estas estratégias simples, este espaço foi otimizado, colaborando também para melhorar a motivação pela disciplina e obter um desempenho acadêmico mais satisfatório, pois um laboratório limpo e organizado induz a comportamentos de empenho e seriedade às tarefas que ali se desenvolvem.

Ao final do semestre, registrou-se a sugestão manifestada pela maioria dos participantes desta experiência de serem realizados trabalhos de campo conjuntos entre alunos dos cursos de Geologia e Geografia, o que representaria uma vivência enriquecedora que reforçaria o caráter multidimensional das ciências da Terra. Esta proposta é bastante interessante para quaisquer cursos acadêmicos que possuam maiores afinidades, favorecendo uma concepção sistêmica de mundo, como bem lembrou Capra (1982) ao afirmar que o mundo é uma totalidade de sistemas integrados que não podem ser reduzidos a fragmentos de ciências estanques.

\section{Considerações Finais}


Refletindo sobre interdisciplinaridade, que a Geografia acolhe em suas múltiplas vertentes, Santos (2008) salienta a necessidade de se interdigitar as diferentes áreas do saber científico (uma perspectiva transdisciplinar) e não somente apresentar saberes paralelos (a perspectiva interdisciplinar) para obter uma formação universitária integral nos cursos de Geografia. O autor ainda comenta que estudo e a pesquisa cooperativa são o melhor caminho para o legítimo diálogo entre as ciências e o verdadeiro processo global de investigação.

Muitas das dificuldades que inibem o bom aproveitamento do ensino oferecido em nossas universidades podem ser solucionadas com ações simples de cooperação interdepartamental, bastando para tanto um rearranjo cotidiano ou um melhor aproveitamento das instalações físicas, que antes de serem propriedades de quaisquer setores, devem servir à universidade como um todo. Tornar um espaço utilizável para mais de um curso, não significa, do ponto de vista departamental, perdê-lo e, sim, multiplicá-lo e otimizá-lo em benefício dos alunos e da própria universidade, que assim tem a oportunidade de formar recursos humanos melhor preparados para contribuir para o crescimento e bem-estar da sociedade em geral.

Do mesmo modo, os recursos humanos, as bolsas e monitorias, podem transcender os limites dos cursos, dos programas e dos departamentos, passando a contribuir com novos olhares para o aprimoramento dos saberes, podendo propor novas formulações não só de conteúdo ou enfoque, mas de práticas mais motivadoras e efetivas. A aproximação entre disciplinas afins favorece ideias inovadoras e torna o olhar mais reflexivo (Morin, 2000), capaz de ver além do estabelecido e de romper com os postulados por vezes imutáveis existentes na academia (Lima, 2001), quer por inércia, quer por convicção de que o que está funcionando é o melhor. Porém, aperfeiçoar é evoluir, e a criatividade e a inovação nas ciências são cada vez mais necessárias no mundo globalizante e de velocidades vertiginosas em que vivemos. Assim, a contínua cooperação entre geógrafos e geólogos poderia provocar insights preciosos para a melhoria na formação e para o desenvolvimento destes profissionais.

As ações relacionadas à educação, por definição, devem ter a capacidade de transformar os alunos através de atitudes e práticas sociais concomitantemente ao desenvolvimento do conhecimento e de competências, nas quais os próprios educandos possam ser capazes de participar e avaliar (Morin, 2002). Nas gerações contemporâneas, a transformação de valores e de paradigmas deve se direcionar para uma visão de mundo impregnada pela incerteza, pela diversidade e constante reconstrução. Para tanto, sempre é preciso buscar novas soluções, criar inusitadas conexões e inovar.

\section{Conclusões}

Considerando que as práticas humanas são norteadas por um contexto teórico previamente formulado (Luckesi, 2000), as ações inovadoras aqui relatadas, propostas e desenvolvidas em cooperação 
interdepartamental na Universidade Federal do Ceará, mostraram ser viáveis e facilmente adaptáveis, como solução que pode ser adotada por outros cursos com disciplinas afins (como Matemática e Física, Biologia e Química, etc.), onde a ausência de atividades práticas tem comprometido o interesse e o rendimento dos estudantes.

As atividades em laboratório, o manuseio de amostras e a maneira despojada de revisar os conceitos apresentados nas aulas teóricas resultaram no aumento de motivação e na participação efetiva dos alunos do Departamento de Geografia em todas as aulas, com melhor compreensão dos temas trabalhados e maior rendimento. O diálogo estabelecido entre estudantes graduandos e pós-graduandos de Geologia e de Geografia também desenvolveu o interesse mútuo em aprimorar as aulas da disciplina de Geologia Geral, demonstrado pelo contínuo esforço em planejar atividades ou efetuar perguntas instigantes e desafiadoras.

\section{Agradecimentos}

Somos gratos, pelo apoio no desenvolvimento das atividades aqui relatadas, em especial ao professor geólogo José de Araújo Nogueira Neto, sem o qual este trabalho não teria iniciado, e a professora Simone Borges (então Coordenadora PROPAG/REUNI do Centro de Ciências-UFC) por sempre se dispor a discutir e contribuir sobre várias questões aqui tratadas. Aos colegas e alunos que participaram ativamente na implantação das mudanças relatadas (e que em muitas vezes representaram a própria mudança), somos igualmente muito gratos.

\section{REFERÊNCIAS}

CAPRA, F. O ponto de mutação: a ciência, a sociedade e a cultura emergente. São Paulo: Círculo do Livro, 1982. 449p.

DEMO, P. Conhecimento moderno: sobre ética e intervenção do conhecimento. $4^{\mathrm{a}}$ ed. Petrópolis: Vozes, 2001. 318p.

FERREIRA, M.G.V.X. O ensino de geologia aos não geólogos. In: CONGRESSO BRASILEIRO DE GEOLOGIA, 36, Natal, Anais, SBG: 1990. 538-543.

HESSEL, M.H.R. A Paleontologia na universidade: um desafio didático. In: SIMPÓSIO SOBRE ESPECIALIZAÇÃO EM ENSINO DE GEOCIÊNCIAS NO 3º GRAU, Campinas, Anais, UNICAMP: 1990. $49-57$.

LIMA, E.C.L. Os labirintos de um novo olhar. In: F.B. OLIVEIRA \& M.L. FORTUNATO (eds) Ensaios: construção do conhecimento, subjetividade, interdisciplinaridade. João Pessoa: Editora Universitária/UFPB: 2001. 51-65.

LUCKESI, C. et al. Fazer universidade: uma proposta metodológica. São Paulo: Cortez, 2000. 232p.

MORIN, E. Complexidade e transdisciplinaridade: a reforma da universidade e do ensino fundamental. Natal: EDUFRN, 1999. 58p.

MORIN, E. A cabeça bem-feita: repensar a reforma, reformar o pensamento. $2^{\mathrm{a}}$ ed. Rio de Janeiro: Bertrand Brasil, 2001. 128p.

MORIN, E. Ciência com consciência. Rio de Janeiro: Bertrand Brasil, 2002. 350p.

OLIVEIRA, F.B. Conhecimento, ética e arte. In: F.B. OLIVEIRA \& M.L. FORTUNATO (eds) Ensaios: construção do conhecimento, subjetividade, interdisciplinaridade. João Pessoa: Editora Universitária/UFPB: 2001. 33-50. 
PIAGET, J. Ensaios de lógica operatória. Porto Alegre: Globo, 1976. 172p.

PORTOCARRERO, V. (org.) Panorama do debate acerca da ciência. In: Filosofia, Historia E Sociologia Das Ciencias 1: abordagens contemporâneas. Rio de Janeiro: FIOCRUZ, 1998. 268p.

SANTOS, B.S. Um discurso sobre as ciências. $4^{a}$ ed. São Paulo: Cortez, 1988. 94p.

SANTOS, B.S. A crítica da razão indolente. $6^{a}$ ed. São Paulo: Cortez, 2007. 415p.

SANTOS, M. Por uma Geografia nova: da crítica da Geografia a uma Geografia crítica. $6^{a}$ ed. São Paulo: EDUSP, 2008. 285p.

SEEMANN, J. Mapas e percepção ambiental: do mental ao material e vice-versa. Olam Ciência e Tecnologia. Rio Claro, 3(1): 2003. 200-223.

SIQUEIRA NETO, A.C. Desafio e entusiasmo como estratégia de aprendizagem. Páginas Abertas, São Paulo, 26: 2006. 14-16. 